\title{
Mirror Neurons of Ventral Premotor Cortex Are Modulated by Social Cues Provided by Others' Gaze
}

\author{
Gino Coudé, Fabrizia Festante, Adriana Cilia, Veronica Loiacono, Marco Bimbi, Leonardo Fogassi, \\ and Pier Francesco Ferrari \\ Dipartimento di Neuroscienze, Università di Parma, 43100 Parma, Italy
}

\begin{abstract}
Mirror neurons (MNs) in the inferior parietal lobule and ventral premotor cortex (PMv) can code the intentions of other individuals using contextual cues. Gaze direction is an important social cue that can be used for understanding the meaning of actions made by other individuals. Here we addressed the issue of whether PMv MNs are influenced by the gaze direction of another individual. We recorded single-unit activity in macaque PMv while the monkey was observing an experimenter performing a grasping action and orienting his gaze either toward (congruent gaze condition) or away (incongruent gaze condition) from a target object. The results showed that one-half of the recorded MNs were modulated by the gaze direction of the human agent. These gaze-modulated neurons were evenly distributed between those preferring a gaze direction congruent with the direction where the grasping action was performed and the others that preferred an incongruent gaze. Whereas the presence of congruent responses is in line with the usual coupling of hand and gaze in both executed and observed actions, the incongruent responses can be explained by the long exposure of the monkeys to this condition. Our results reveal that the representation of observed actions in PMv is influenced by contextual information not only extracted from physical cues, but also from cues endowed with biological or social value.
\end{abstract}

Key words: gaze; grasping; mirror neuron; premotor cortex; social cues

Significance Statement

In this study, we present the first evidence showing that social cues modulate MNs in the monkey ventral premotor cortex. These data suggest that there is an integrated representation of other's hand actions and gaze direction at the single neuron level in the ventral premotor cortex, and support the hypothesis of a functional role of MNs in decoding actions and understanding motor intentions.

\section{Introduction}

When observing another individual grasping an object, at least two main features related to the observed agent need to be coded in the observer's brain: the movement itself of reaching and grasping, and the gaze direction of the observed agent. These two features are known to be tightly linked together, as for instance, gaze normally anticipates arm movement (Flanagan and Johansson, 2003). The observer must decode these two relevant sources of information to understand others' actions and possibly predict the outcome of the ongoing behavior.

\footnotetext{
Received Aug. 25, 2015; revised Jan. 8, 2016; accepted Jan. 31, 2016.

Author contributions: G.C. and P.F.F. designed research; G.C., F.F., A.C., and V.L. performed research; G.C. and M.B. contributed unpublished reagents/analytic tools; G.C., F.F., and A.C. analyzed data; G.C., L.F., and P.F.F. wrote the paper.

This work was supported by the Division of Intramural Research, NICHD, and NIH P01HD064653.

The authors declare no competing financial interests.

Correspondence should be addressed to Dr. Gino Coudé, Dipartimento di neuroscienze, Università di Parma, Via

Volturno 39, 43100 Parma, Italy. E-mail: gino.coude@nemo.unipr.it.

DOI:10.1523/JNEUROSCI.3220-15.2016

Copyright $\odot 2016$ the authors $\quad 0270-6474 / 16 / 363145-12 \$ 15.00 / 0$
}

The discovery of mirror neurons (MNs) has contributed to clarify how the motor system can decode other's grasping action. MNs fire both when the monkey executes an action and when it observes a similar action performed by another individual (Gallese et al., 1996; Fogassi et al., 2005). The same motor programs necessary to perform an action are recruited during the observation of the action. According to the "direct matching hypothesis" (Gallese et al., 1996; Rizzolatti et al., 1996, 2001; Iacoboni et al., 1999) this neuronal behavior would allow an individual to exploit the internal motor representations for understanding others' actions.

The neurophysiological work of the last few years has revealed important characteristics of MNs. For example, MNs are modulated by the space in which the grasping action is occurring and by the perspective from which the grasping action is observed (Caggiano et al., 2009, 2011, 2012). Interestingly, the presence of MNs in parietal and premotor cortex discharging differently during the observation of grasping actions aimed at different goals (i.e., grasping to eat or grasping to place into a container) prompted the idea that they also may play a major role in decoding others' 
intention (Fogassi et al., 2005; Bonini et al., 2011). These data also suggest that MNs receive and integrate information coming from several areas.

How the motor system integrates information regarding others' action with their gaze direction remains unclear. The capacity to decode others' gaze direction is fundamental in social relations as it may provide important information regarding others' intentions. It is also considered as a building block for the emergence of complex cognitive skills. Strong evidence indicates that the superior temporal sulcus (STS) is one of the key nodes for the representation of gaze direction. The role of STS was first studied by Perrett et al. (1985) who recorded single-unit activity in the monkey anterior superior temporal sulcus (STS) and identified cells that are tuned to the same direction conveyed by body posture, head orientation, or gaze direction. Also in humans, gaze perception (Puce et al., 1998; Pelphrey et al., 2003) and coding gaze direction (Calder et al., 2007; Carlin et al., 2011) are associated with STS activation.

It has been shown that the signals from STS regions are sent to different cortical areas involved in visual orienting behavior such as the lateral intraparietal region (LIP) and prefrontal cortex (Seltzer and Pandya, 1989a,b, 1994, 2009; Gerbella et al., 2010). Interestingly, a neurophysiological study performed in the monkey LIP has discovered that some neurons are sensitive to others' gaze. They mirrored observed attention by firing both when the subject looked in the preferred direction of the neurons, and when the monkey observed another monkey looking in the preferred direction of the neurons (Shepherd et al., 2009). This result is also consistent with the idea that, in decoding information regarding other's gaze direction, the same motor programs used to shift attention are recruited.

Despite the accumulated knowledge about the neural underpinnings responsible for decoding others' actions and gaze, how these two different inputs are integrated in the brain remains unknown. To address this question, we investigated the activity of hand MNs in the ventral premotor (PMv) cortex of the monkey during the observation of grasping actions in which the observed agent shifted his/her head/gaze in a direction congruent or incongruent with that of reaching and grasping (hereafter referred as "grasp direction"). Here we show that one-half of the recorded F5 MNs are modulated by the gaze direction, providing an integrated representation of other's hand action and gaze that might be useful to decode and predict others' actions and intentions.

\section{Materials and Methods}

Animals and surgical procedures. Two captive-born and individually housed adult female rhesus macaques (Macaca mulatta) served as subjects (M1 and M2). The animal handling, as well as surgical and experimental procedures, complied with the European guidelines (86/609/EEC 2003/65/EC Directives and 2010/63/EU) and Italian laws in force on the care and use of laboratory animals, and were approved by the Veterinarian Animal Care and Use Committee of the University of Parma (Prot. 78/12 17/07/2012) and authorized by the Italian Health Ministry (D.M. 294/2012-C, 11/12/2012). The monkeys were housed and handled in strict accordance with the recommendations of the Weatherall Report about good animal practice. The wellbeing and health conditions of the monkeys were constantly monitored by the institutional veterinary doctor of the University of Parma.

A titanium head post (Crist Instrument) was surgically implanted on the skull using titanium screws. A CILUX recording chamber $(18 \times 18$ $\mathrm{mm}$, Alpha-Omega) was stereotaxically implanted and secured with dental cement. For both procedures, each animal was deeply anesthetized with ketamine hydrochloride ( $5 \mathrm{mg} / \mathrm{kg}$, i.m.) and medetomidine hydro- chloride $(0.1 \mathrm{mg} / \mathrm{kg}$, i.m. $)$ and its heart rate, temperature, and respiration were carefully monitored and kept within physiological range. Pain medication was routinely given after surgery: (dexamethasone, $2 \mathrm{mg} / \mathrm{kg}$, every $12 \mathrm{~h}$, from $1 \mathrm{~d}$ before to $3 \mathrm{~d}$ after surgery; ketoprofen, $5 \mathrm{mg} / \mathrm{kg}$, every $12 \mathrm{~h}$ for $3 \mathrm{~d}$ following surgery).

Behavioral procedures: action observation task. The monkey was seated facing a table $(60 \times 60 \mathrm{~cm})$ onto which two small objects $(2$ metallic cubes that served as target objects) were placed out of reach; one on the right and one on the left side of the experimenter (or corresponding to the ipsilateral and contralateral side, with respect to the left side recorded hemisphere). The experimenter (hereafter called "agent") sat at the other end of the table, in front of the monkey, with his right hand resting on a central platform located on the table between the two targets. The monkey was trained to orient its gaze successively across two different fixation windows. The location of the first window $\left(15^{\circ} \times 15^{\circ}\right)$ was on the agent's face (face window), whereas the second $\left(22^{\circ} \times 22^{\circ}\right)$ was on either the left or right target object (target window). The experimental setup, the timeline of events, and the task are illustrated in Figure 1. A task trial started if the monkey was leaning its hand on a handle attached to the table (Fig. 1A). After 1000 $\mathrm{ms}$, a first LED instructed the monkey to fixate the first window for $1000 \mathrm{~ms}$ (face window; Fig. 1B). After $500 \mathrm{~ms}$, the agent either shifted his head/gaze, or not, toward or away from the target object, according to the tested condition (see Experimental conditions; Fig. 1C). After $500 \mathrm{~ms}$, the first LED was turned off, a second LED was turned on instructing the monkey to shift its gaze to the target location (the target window) and to maintain fixation in that second window for $1000 \mathrm{~ms}$ (Fig. 1D). While the monkey was fixating the target object, the agent was cued to either grasp the target object or not to move (Fig. 1E). A juice reward was delivered after a randomized period of 200-300 $\mathrm{ms}$ if the monkey correctly fixated the windows for the established period of time (Fig. $1 F$ ). The monkey was required to hold the handle throughout the entire trial to get the reward. The release of the handle automatically aborted the trial. The distance between the two fixation windows is $\sim 30^{\circ}$ of the visual angle. The task was designed such as the monkey could see the target object while fixating the agent's face and conversely, could see the agent's face while fixating the target object.

Experimental conditions. The experimental conditions are illustrated in Figure 2. We tested four experimental conditions in which the monkey observed the agent's behavior. This behavior was performed either in the contralateral or ipsilateral direction while manipulating five gaze conditions. The conditions were as follows: Figure $2 A$, congruent gaze: the agent directed his gaze toward the target object; Figure $2 B$, incongruent gaze: the agent directed his gaze away from the target object; Figure $2 C$, no gaze shift: the agent kept looking toward the monkey (without staring at its eyes) and did not orient his gaze toward any direction; Figure $2 D$, no gaze shift + spotlight: the agent, as in the previous condition, kept looking toward the monkey and did not orient his gaze in any direction, but here a spotlight highlighted the target object; Figure 2E, no grasping: the agent directed his gaze toward the target object but did not perform any grasping and kept his hand on the starting platform. The gaze shift or the spotlight started $1500 \mathrm{~ms}$ after the onset of the trial.

Data recording. Neuronal activity was recorded with a linear multisite electrode (16-channel, $250 \mu \mathrm{m}$ spacing; U-probe, Plexon) and digitalized at $40 \mathrm{kHz}$ using the Omniplex 16-channel recording system (Plexon). Eye movements were monitored throughout the experiment using a customized eye tracker (University of Tuebingen) equipped with a CCD camera (Ganz, ZC-F11CH4). The left pupil was lit with infrared LEDs, allowing the eye position (sampled at $50 \mathrm{~Hz}$ ) to be tracked by the CCD camera. The X and Y coordinates of the eye position were fed to the Omniplex recording system. The fixation task (including window size, fixation duration, reward delivery, etc) was computer-controlled through a customized Labview program. Contact-detection panels (Crist Instrument) were used to record the exact moment in which the agent's hand touched the target. This event was used to align the neuronal activity recorded for every trial in all conditions.

The recording sessions were performed on well trained monkeys having reached a $80 \%$ correct trials criterion for the fixation in the task 

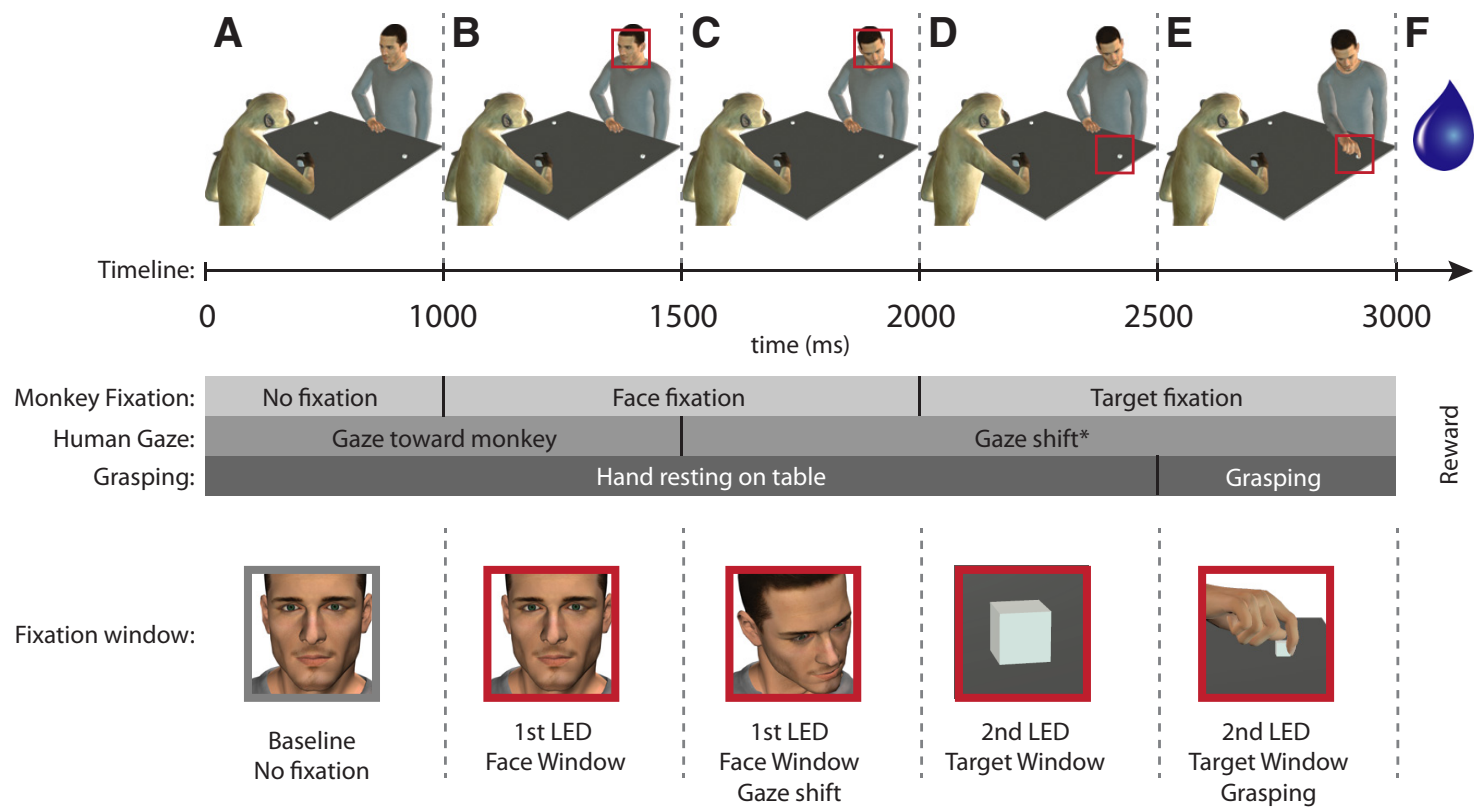

Figure 1. Task illustration $(\boldsymbol{A}-\boldsymbol{F})$, timeline and fixation windows. $\boldsymbol{A}$, The monkey and the agent are passively leaning their right hand on the table. $\boldsymbol{B}$, The monkey is cued to fixate on a space window corresponding to the agent's face (face window). $\boldsymbol{C}$, The agent is cued to shift his gaze toward the target. $\boldsymbol{D}$, The monkey is cued to fixate on the space window corresponding to the target object (target window). $\boldsymbol{E}$, The agent is cued to grasp the object at the location where the monkey is fixating. $\boldsymbol{F}$, The monkey receives a liquid reward if he fixates for at least one second on each of the windows. The red squares indicate in which fixation window (face window or target window) the monkey was required to fixate. Note: the figure illustrates a contralateral grasping with congruent gaze.

described above. Monkeys 1 and 2 were trained four times a week for 8 and 7 months, respectively. We collected usable $\mathrm{MN}$ data in 14 sessions recorded over a period of 5 months form Monkey 1 and in 11 sessions recorded over 4 months from Monkey 2. During insertion of the electrode shaft in the brain, we ensured that the topmost electrode was positioned under the dura, but remained outside of the cortex, so that it could be used as a reference channel. Of the 15 available recording channels, two were dedicated to eye movements ( $\mathrm{X}$ and $\mathrm{Y}$ coordinates). The remaining 13 channels were used for single-unit recording. The multielectrode was lowered in the brain through the intact dura and the general properties of the neurons were tested. When putative mirror properties for grasping were found, we waited $\sim 1$ h to allow the neural activity to stabilize and then started to record single units using the behavioral protocol described above.

Preliminary testing of neuronal activity. Before proceeding with the neural testing using our behavioral protocol, single-unit and multiunit activity were systematically tested for visuomotor properties to identify recording sites endowed with MN activity (Rozzi et al., 2008; Maranesi et al., 2012). Briefly, we required the monkey to grasp food items in various conditions (i.e., with eyes closed, or without flexing the wrist, elbow, or shoulder) enabling us to disentangle neuronal activity related to visual stimulation, reaching or grasping objects. Also, to exclude the possible presence of mouth-related responses, we tested any neural activity changes related to the delivery of small pieces of food directly into the mouth while the monkey's eyes were closed. Finally, visual properties were studied by presenting the monkey with $3 \mathrm{D}$ objects (e.g., food items and solids) of different shape, size, and orientation, moved in various space locations, directions, and distances from the monkey, as well as different manual actions performed by the experimenter.

Data analysis. Neuronal spikes waveforms were classified offline into units using commercial spike-sorting software (OfflineSorter, Plexon). For each of the 13 electrodes, a mean of $2.7 \mathrm{U}$ were isolated. The neural response selectivity was determined for each neuron comparing the spike frequency for each trial across two epochs (baseline and grasping, described below) and seven conditions including congruent gaze ipsilateral, congruent gaze contralateral, incongruent gaze ipsilateral, incongruent gaze contralateral, no gaze shift, no gaze shift with spotlight and no grasping. The statistical analysis consisted in a $2 \times 7$ repeated-measures
ANOVA (factors: epochs and conditions) followed by a Newman-Keuls post hoc test, all with a $0.05 \alpha$ level. The two epochs had a $600 \mathrm{~ms}$ duration and were precisely calculated with reference to the digital events. The baseline epoch corresponded to a time period in which the monkey remained still and was leaning his hand on the handle. This epoch lasted from 1000 to $400 \mathrm{~ms}$ before the beginning of the fixation of the agent's face (face window) signaled by the lighting of a LED. The Grasping epoch started $300 \mathrm{~ms}$ before the agent's hand contact with the object and finished $300 \mathrm{~ms}$ after that same event. In the no grasping condition we did not have the event of the agent's hand contact with the object to define the "grasping" epoch, we therefore used for data alignment the mean time at which the grasping normally occurred, after the target window fixation cue, in the other conditions.

Additional controls were performed to better characterize the MNs specificity of gaze-modulation response to grasping observation on the MNs. To do so, we analyzed MNs modulation pattern in relation to two separate gaze events: (1) the observed agent's gaze shift and (2) the monkey's own gaze shift.

First, we tested possible firing differences related to agent's gaze shifts and aligned the neuronal discharge with the face fixation event and defined two epochs of $300 \mathrm{~ms}$ duration each: baseline and agent's gaze shift. The baseline epoch consisted in a time period in which the monkey fixated the agent's face before the agent's gaze shift (from 300 to $600 \mathrm{~ms}$ after face fixation cue) and this corresponded to $\sim 1200$ $1500 \mathrm{~ms}$ on the timeline of Figure 1. The agent's gaze shift epoch corresponded to a period in which the monkey fixated the agent's face just after the agent shifted his gaze toward the target (from 800 to 1100 $\mathrm{ms}$ after face fixation) and this corresponded to $\sim 1600-1900 \mathrm{~ms}$ on the timeline of Figure 1.

Second, we tested whether the monkey's own gaze direction had an influence on MNs' activity and aligned the neuronal discharge with the monkey's own gaze shifts. We tested the neurons during the saccades made by the monkey to shift its gaze from the face window (Fig. $1 B, C$ ) to the target window (Figure $1 D, E$ ). We carefully aligned the neuronal activity with the beginning of the saccade using as a criterion the moment in which the eye of the monkey reached a velocity of $60 \%$ in the $x$-axis, either toward the ipsilateral or contralateral side according to the experimental condition tested. This criterion yielded a 
A

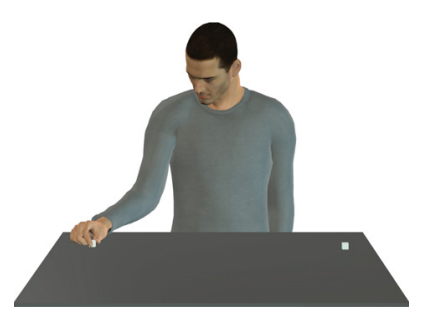

Congruent gaze
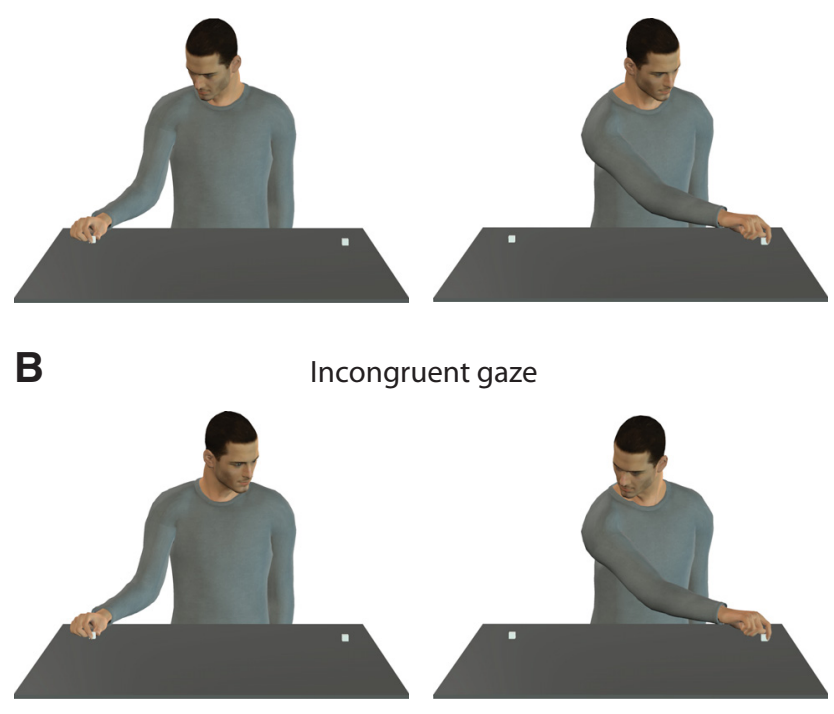

B

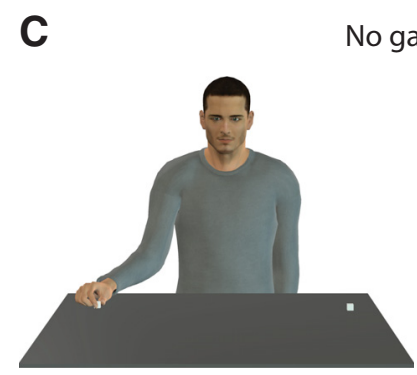

No gaze shift
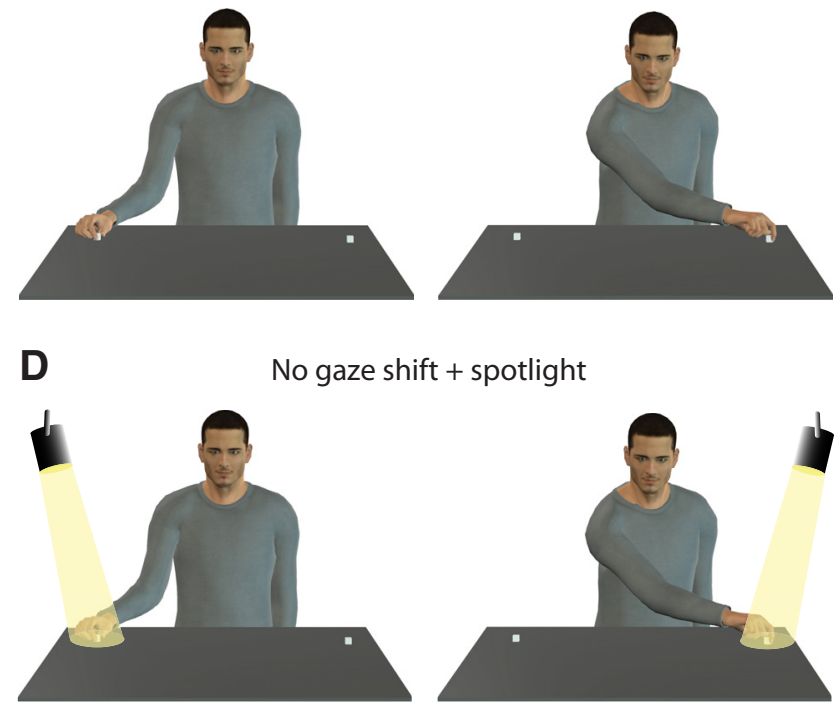

E No grasping
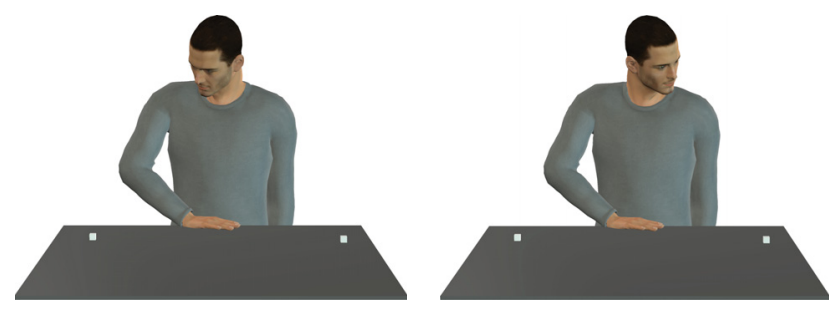

Figure 2. Experimental conditions. $\boldsymbol{A}$, Congruent gaze: the gaze direction is congruent with grasping direction, either in the ipsilateral or contralateral direction. $\boldsymbol{B}$, Incongruent gaze: the gaze direction is directed away from with respect to the grasping direction, either in the ipsilateral or contralateral direction. C, No gaze shift: the gaze direction remains central without any gaze shift and the grasping occur either toward the ipsilateral or contralateral direction. $\boldsymbol{D}$, No gaze shift + spotlight: in addition to central gaze, a spotlight lit the grasping location and the grasping occurs either on the ipsilateral or contralateral direction. $\boldsymbol{E}$, No grasping: the gaze direction is either ipsilateral or contralateral but no reaching/grasping occurs. robust and consistent alignment with the beginning of the saccade. We defined two $400 \mathrm{~ms}$ epochs: a baseline epoch: -700 to -300 before monkey saccade and a monkey's gaze shift epoch: $-200 \mathrm{~ms}$ before saccade to $200 \mathrm{~ms}$ after it. We choose epochs of $400 \mathrm{~ms}$ duration to account for a possibly wide range of discharge onset with respect to the saccade (i.e., from anticipatory to time-locked).

For both sets of data (aligned on agent's gaze and on monkey's gaze) the neuronal discharge of each neuron was compared in the two epochs described above. For each neuron, we applied paired $t$ test with a $0.05 \alpha$ level with a Bonferroni correction.

Population analysis. The population analysis was performed by constructing a spike-density function for each neuron by averaging the spike frequency for each $20 \mathrm{~ms}$ bins across trials. The baseline activity (mean spike activity during the baseline epoch) was subtracted from that of each bin. The data were then normalized by dividing the spike frequency within each bin by the maximum absolute value found across all bins. The result is a discharge rate ranging between 1 and -1 for each neuron. The spike density function was smoothed using a Gaussian kernel of 30 ms using the following formula:

$$
\frac{e^{-\frac{t^{2}}{2 \sigma^{2}}}}{\sqrt{2 \pi \sigma}}
$$

where $\sigma$ corresponds to the width $(30 \mathrm{~ms})$ of the smoothing function and $t$ the $n$th successive bin in the data vector.

The population curve was computed as the algebraic sum of the spike frequency for each bin of each neuron. The statistical differences between populations of neurons were calculated based on the firing rate during the grasping epoch. One-way repeated-measure ANOVAs were calculated, followed by Newman-Keuls post hoc procedures.

\section{Results}

The activity of 1195 neurons was recorded from PMv of two monkeys. One-hundred seventy-four of them discharged both when the animals performed active grasping movements and when they observed the same action performed by the agent. We hereafter refer to these neurons as "mirror neurons." Note that none of these neurons showed a significant discharge in the nograsping condition.

\section{Gaze direction effect}

The main scope of the present work is to assess the effect of the congruence of gaze direction with grasping direction on the visual discharge of MNs. Figure 3 summarizes the gaze properties of the recorded MNs. We found that $47 \%$ (81 neurons) of the MNs had a significant preferential modulation for one type of gaze direction, i.e., either congruent or incongruent with respect to the grasping direction, showing that the congruence between gaze direction and grasping direction is an important parameter that modulates MNs. Among gaze-modulated MNs, approximately one-half ( $n=41,24 \%$ of MNs) preferred the congruent gaze condition, the other one-half ( $n=40,23 \%$ of MNs) preferred the incongruent gaze.

\section{Interactions between gaze and reaching/grasping direction}

Because our task was designed to study the congruence between grasping direction and gaze direction, it necessarily involved two grasping target locations: ipsilateral and contralateral with respect to the recording (left) hemisphere. We tested MNs during grasping toward the ipsilateral and contralateral side (see Materials and Methods, Behavioral procedures) and found that, regardless of the gaze direction involved, $57 \%$ of them had a significant grasp direction preference. Interestingly, combining together gaze and grasp direction data, we found that most of the gaze-modulated neurons were in fact also modulated by grasp 


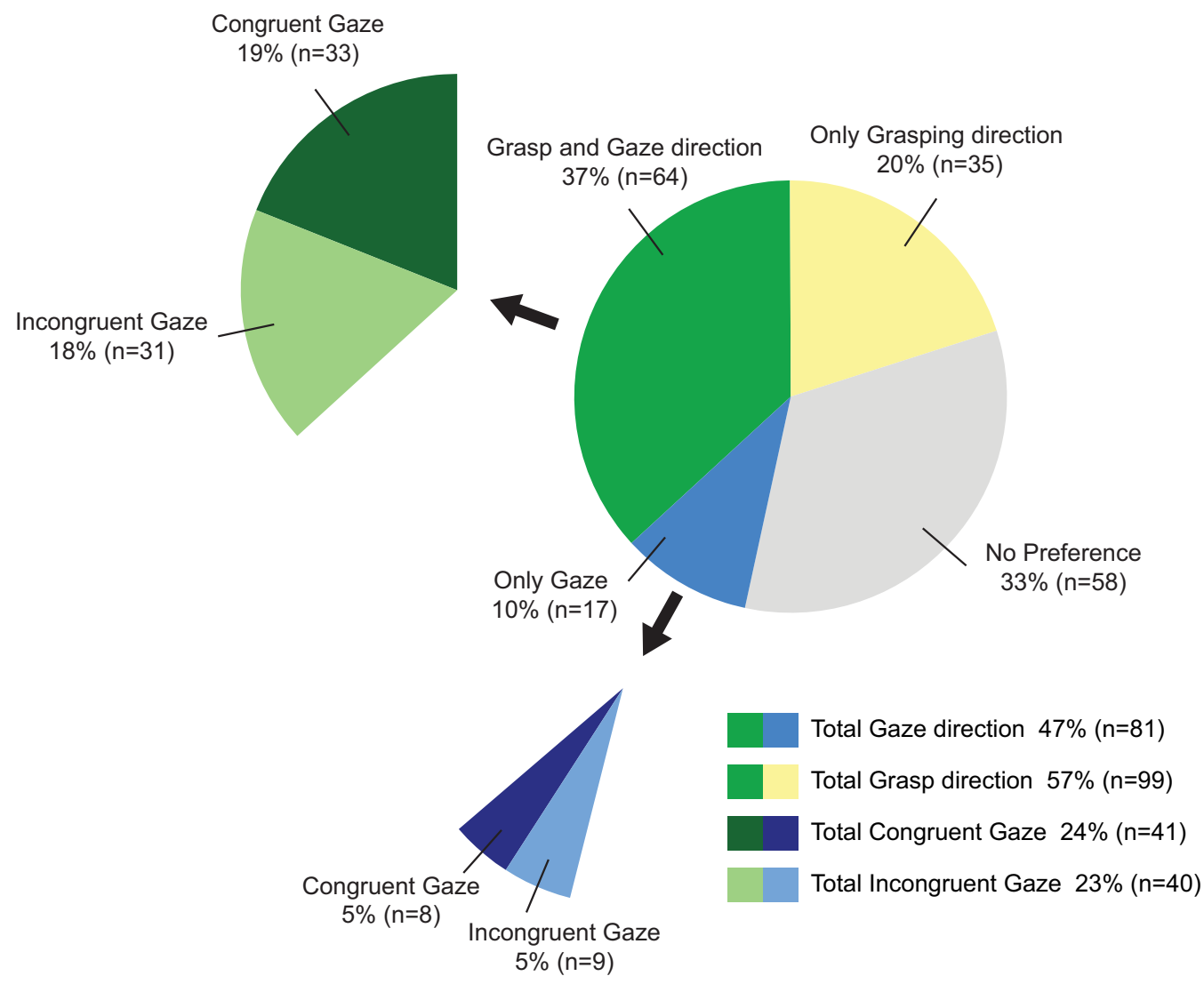

Figure 3. Proportion of MNs having a gaze direction preference. Forty-seven percent $(n=81)$ of the MNs had a significant preferential modulation for one type of gaze direction, i.e., either congruent or incongruent with respect to the grasping direction. The preference ratio is evenly distributed between congruent gaze (total congruent gaze, 24\%; $n=41$ ) and incongruent gaze (total incongruent gaze, $23 \% ; n=40$ ) gaze. The relationship between gaze preference and grasping direction preference shows that the majority of the neurons having a gaze preference also have a grasping direction preference (grasp and gaze direction, $n=64$, vs only gaze, $n=17$ ).

direction. Indeed, 79\% $(n=64)$ of the total 81 gaze-modulated neurons have also a preference for grasping direction (Fig. 3). Twenty-one percent $(n=17)$ of the gaze-modulated neurons did not have a preference for grasping direction. Figure 4 shows the spatial distribution of MNs that are gaze direction modulated, grasp direction modulated, and gaze and grasp direction modulated, according to cortical depth and position on a anteroposterior axis. The figure shows that there is no clear segregation pattern among these three main neuronal types. Two examples of gaze and grasp modulated neurons are illustrated in Figure 5. The unit in Figure $5 A$ shows a congruent gaze preference in ipsilateral grasping direction (green), whereas in Figure $5 B$ a neuron preferring incongruent gaze with grasping in the contralateral direction (yellow) is represented.

We were interested to know to which extent the gaze preference was linked to the grasping direction preference. We plotted neuronal population data according to their preferences for gaze (congruent or incongruent) and grasp direction (ipsilateral or contralateral) using the 59 excitatory neurons we found that were having both a gaze direction preference and a grasp direction preference. The four categories resulting from the preference combinations for gaze and grasp direction are the following: (1) preferred gaze direction with preferred grasp direction $(\mathrm{PGz}+\mathrm{PGr})$, (2) non-preferred gaze direction with preferred grasp direction (NGz+PGr), (3) preferred gaze direction with non-preferred grasp direction (PGz+NGr), and (4) nonpreferred gaze direction with non-preferred grasp direction $(\mathrm{NGz}+\mathrm{NGr})$. The results are shown in the population analysis illustrated in Figure $6 A$, in which the neuronal response yielded in the four conditions are compared. A one-way repeated-measure ANOVA revealed significant differences between them $\left(F_{(3,55)}=\right.$ 49.03; $p<0.001)$. Post hoc comparisons showed that neurons tested in $\mathrm{PGz}+\mathrm{PGr}$ condition are firing significantly more than in the other conditions (PGz+PGr vs NGz+PGr, $p<0.0001$; $\mathrm{PGz}+\mathrm{PGr}$ vs PGz+NGr, $p<0.0001 ; \mathrm{PGz}+\mathrm{PGr}$ vs NGz+NGr, $p<0.0001)$. Interestingly, $\mathrm{NGz}+\mathrm{PGr}$ is significantly higher than any gaze (preferred or not) with non-preferred grasp direction $(\mathrm{NGz}+\mathrm{PGr}$ vs PGz+NGr, $p<0.01 ; \mathrm{NGz}+\mathrm{PGr}$ vs $\mathrm{NGz}+\mathrm{NGr}$, $p<0.01$; Fig. $6 B$ ). In other words, the neuronal mirror response in the preferred gaze is amplified only in the preferred grasp direction, whereas in the non-preferred grasp direction, gaze preference neuronal response is absent or its modulatory effect on the neuronal discharge is revoked.

\section{Attentional effects}

In our experiment, gaze direction points toward a target regardless of whether or not it will be grasped. This very likely caused the monkey to shift its attention toward that target. Such behavior has been reported in macaque monkeys (Emery et al., 1997; Ferrari et al., 2000) and could be a potential factor that contributes to the increased modulatory neuronal activity in neurons showing a gaze preference. To take into account this possible confounding factor, we introduced a no gaze shift + spotlight condition in which we replaced the congruent gaze shift by a spotlight highlighting the target object (Fig. 2). Note that the time course for the spotlight activation was the same as for the gaze shift in the congruent gaze condition. We found that 


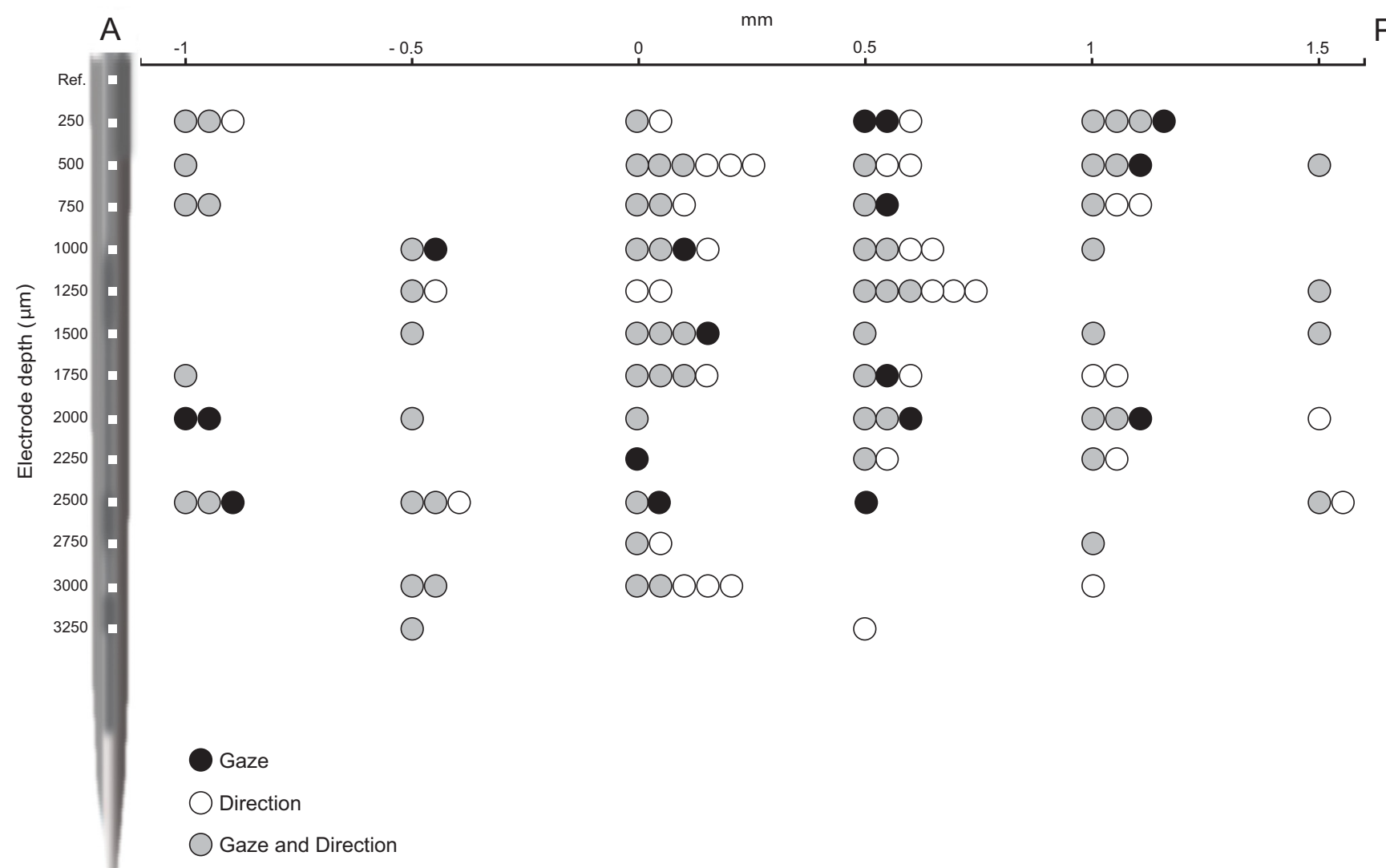

Figure 4. Spatial distribution of MNs according to anteroposterior position ( $x$-axis) and cortical depth ( $y$-axis). Each dot represents a neuron and the color denotes its preference type: gaze direction modulated (black), grasping direction modulated (white), and neurons with both gaze and grasping direction preferences (gray). A schematic view of the linear multisite electrode is shown on the $y$-axis. Note the overall intermingled properties. Anteroposterior $0 \mathrm{~mm}$ corresponds to the midline of the recording chamber. Data are from the two monkeys. $A$, Anterior; $P$, posterior.

for the vast majority of neurons (95\%) the discharge for the preferred gaze was significantly stronger than for the no gaze shift + spotlight condition. In addition, the no gaze shift + spotlight condition itself was not enough to modulate a neuronal preference and there were no significant differences between the no gaze shift + spotlight and the no gaze shift (without spotlight) conditions. Indeed the population analysis of congruent gaze neurons in which the mean neuronal response for congruent gaze, no gaze shift and no gaze shift + spotlight were compared (Fig. $7 A, B$ ) showed a significant differences across conditions (one-way repeated-measure ANOVA $\left(F_{(2,84)}=414.19, p<0.0001\right)$. Post hoc Neuman-Keuls tests showed that the mean congruent gaze response $(0.46 \pm 0.02)$ is significantly higher than no gaze shift + spotlight $(0.46 \pm 0.02$ vs $0.27 \pm 0.03 ; p<0.001)$ and no gaze $\operatorname{shift}(0.46 \pm 0.02$ vs $0.30 \pm 0.03$; $p<0.001)$, but there is no difference between no gaze shift + spotlight and no gaze shift $(0.27 \pm 0.03$ vs $0.30 \pm 0.03$; n.s.; Fig. $7 B)$. Together, these results exclude that a confounding attentional effect imparted by the deictic nature of gaze direction could explain the gaze-type modulation obtained in this experiment.

As a supplementary control of a possible attentional effect underlying the gaze direction effect, we analyzed the oculomotor pattern of the monkeys during grasping observation in the four conditions resulting from the combination of the two directions of gaze and grasping (congruent ipsilateral, congruent contralateral, incongruent ipsilateral, and incongruent contralateral; 228 trials in each condition). These behavioral data indicate that the mean eye position of the monkey during the fixation of the Target window during the grasping motor act is the same for incongru- ent and congruent gaze conditions There was no significant difference in gaze position in degrees of visual angle between the congruent and incongruent gaze conditions for ipsilateral grasping in $x$-axis (congruent: $10.99 \pm 0.04$ vs incongruent: $10.97 \pm$ $0.05 ; t=-0.0536, p=0.96$, n.s.), contralateral grasping in $x$-axis (congruent: $11.00 \pm 0.04$ vs incongruent: $11.00 \pm 0.05 ; t=0.44$, $p=0.66$, n.s.), ipsilateral grasping in $y$-axis (congruent: $11.00 \pm$ 0.07 vs incongruent: $11.07 \pm 0.07 ; t=0.23, p=0.82$, n.s.), and finally, contralateral grasping in $y$-axis (congruent: $11.00 \pm 0.05$ vs incongruent: $11.01 \pm 0.05 ; t=-0.75, p=0.45$, n.s.; two-tailed $t$ test; Fig. 8). We also compared the proportion of successful fixations in the target window (i.e., aiming at the object) for the two monkeys. We found no significant differences in the successful fixation percentage [Monkey 1: congruent trials $(n=442$; $93.43 \% \pm 0.60)$ vs incongruent trials $(n=464 ; 89.82 \% \pm 0.84)$, $z=1.73, p=0.08$; Monkey 2: congruent trials $(n=400 ; 62.59 \%$ $\pm 3.77)$ vs incongruent trials $(n=399 ; 64.72 \% \pm 3.15), z=$ $-0.1, p=0.91$, Wilcoxon signed rank test; Figure 9).

We also verified whether the agent's gaze shift had an impact on the gaze behavior of the monkey. We found that the eye position was stable during the whole face fixation (Fig. 10, eye traces). We did not find any significant differences in eye position between the pre- and the post-gaze shift epochs, neither in the ipsilateral gaze shift $\left(x\right.$-axis diff $=0.01 \pm 0.02^{\circ} ; t=0.75, \mathrm{df}=$ $499, p=0.46$, n.s.; $y$-axis diff $=0.04 \pm 0.02^{\circ} ; t=1.77, \mathrm{df}=499$, $p=0.08$, n.s. $)$, nor for the contralateral direction $(x$-axis diff $=$ $0.00 \pm 0.03^{\circ} ; t=0.12, \mathrm{df}=480, p=0.90$, n.s.; $y$-axis diff $=$ $0.00 \pm 0.02^{\circ} ; t=1.77, \mathrm{df}=480, p=0.70$, n.s.). These behavioral 
A

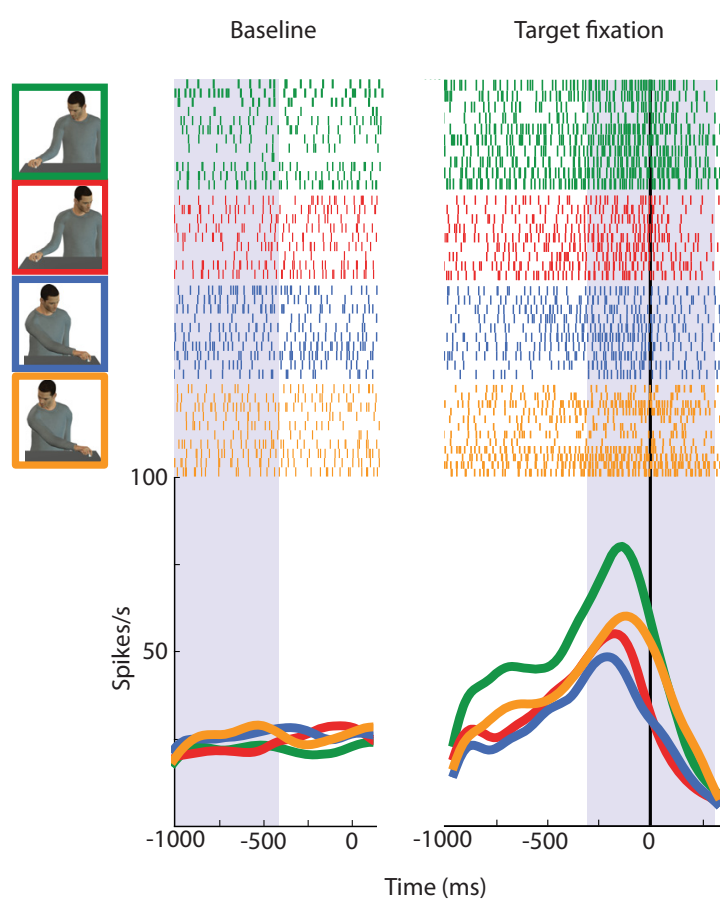

B

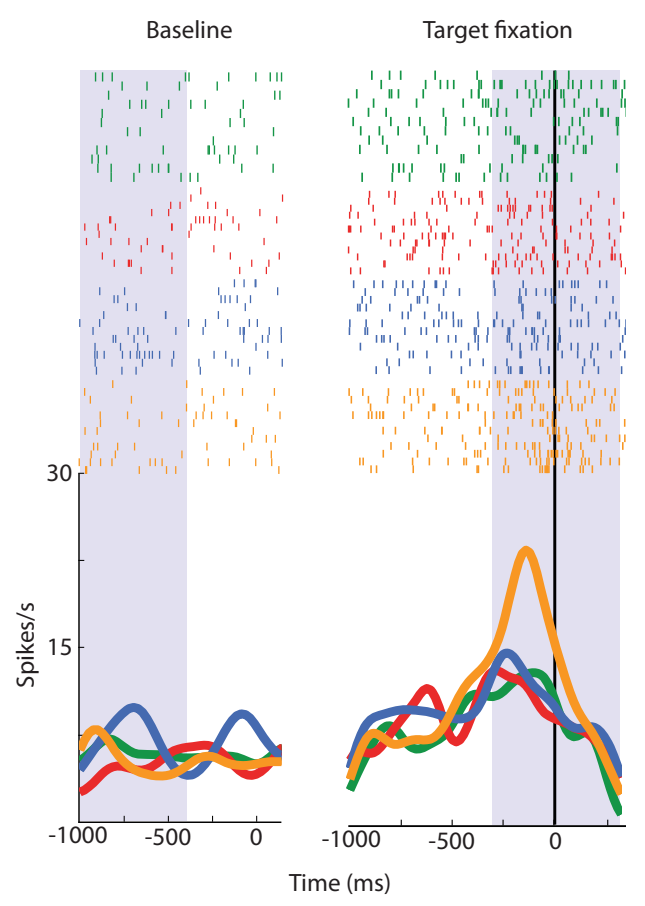

Figure 5. Examples of gaze-modulated neurons. $\boldsymbol{A}$, Unit having a preference for grasping in the ipsilateral grasp direction with congruent gaze (green). $\boldsymbol{B}$, Unit having a preference for grasping in the contralateral grasp direction with incongruent gaze (yellow). The gray shaded areas represents the baseline epoch (from -1000 to $4000 \mathrm{~ms}$ before the face fixation cue) and the grasping epoch ( -300 to $300 \mathrm{~ms}$ around grasping). On the left hand side, trials were aligned on face fixation (i.e., the cue for fixating; vertical black line at $t=0)$. On the right hand side, trials were aligned on grasping (i.e., the agent's contact with the object; vertical black line at $t=0$ ).

A

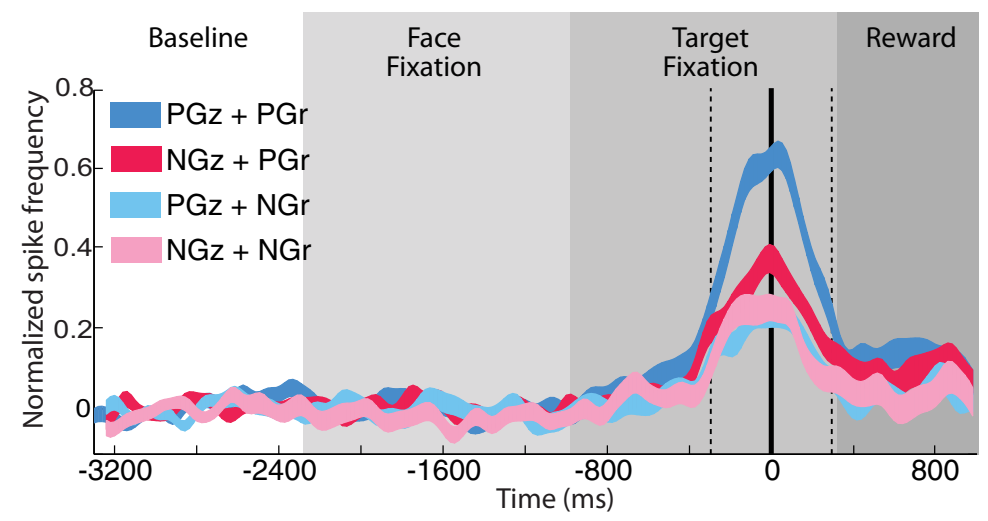

B

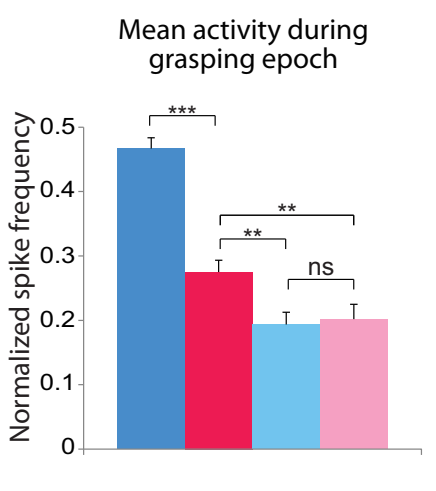

Figure 6. Analysis of gaze-modulated MN population in relation to grasp direction. $\boldsymbol{A}$, Neuronal response during the various phases of a trial for preferred gaze direction with preferred grasp direction (PGz+PGr; dark blue), non-preferred gaze direction with preferred grasp direction (NGz+PGr; red), preferred gaze direction with non-preferred grasp direction (PGz+ NGr; light blue), and non-preferred gaze direction with non-preferred grasp direction ( $\mathrm{NGz}+\mathrm{NGr}$; pink). Normalized activity of a population of 59 excitatory neurons. The vertical thick black line represents the moment at which the contact between hand and object occurred during grasping. The two vertical dashed lines indicate the beginning and the end of the grasping epoch (600 ms). The thickness of the curves represents \pm 1 SE. $B$, Mean normalized neuronal discharge during the grasping epoch. Two-way ANOVA $\left({ }^{*} p<=0.01,{ }^{* *} p<=0.01,{ }^{* * *} p<0.001\right)$.

data show that the monkeys do not tend to follow the gaze direction of the agent but maintain their fixation on the same area of the face fixation window.

As a further control of the specificity of gaze modulation to grasping observation, we verified whether any of the recorded MNs was influenced by the agent's gaze direction per se, independently from grasping observation. We compared the mean neuronal discharge in two epochs of $300 \mathrm{~ms}$ pre- and post-agent gaze shift (see Materials and Methods) and found that none of the MNs showed significant difference in the discharge between these two epochs. Similarly, we tested whether the MN discharge was modulated by the monkey's own gaze shifts. In addition, we compared the neuronal discharge between two epochs, before and during the monkey's gaze shift. We found that none of the MNs had a significant differential discharge between the baseline and the gaze shift epochs in either gaze directions. Figure 10 shows an example of a typical $\mathrm{MN}$ with gaze trace and neuronal activity aligned on: $(A)$ grasping and $(B)$ monkey gaze shift. Note the presence of a discharge for grasping observation $(A)$ and the absence of discharge during gaze shift $(B)$. 

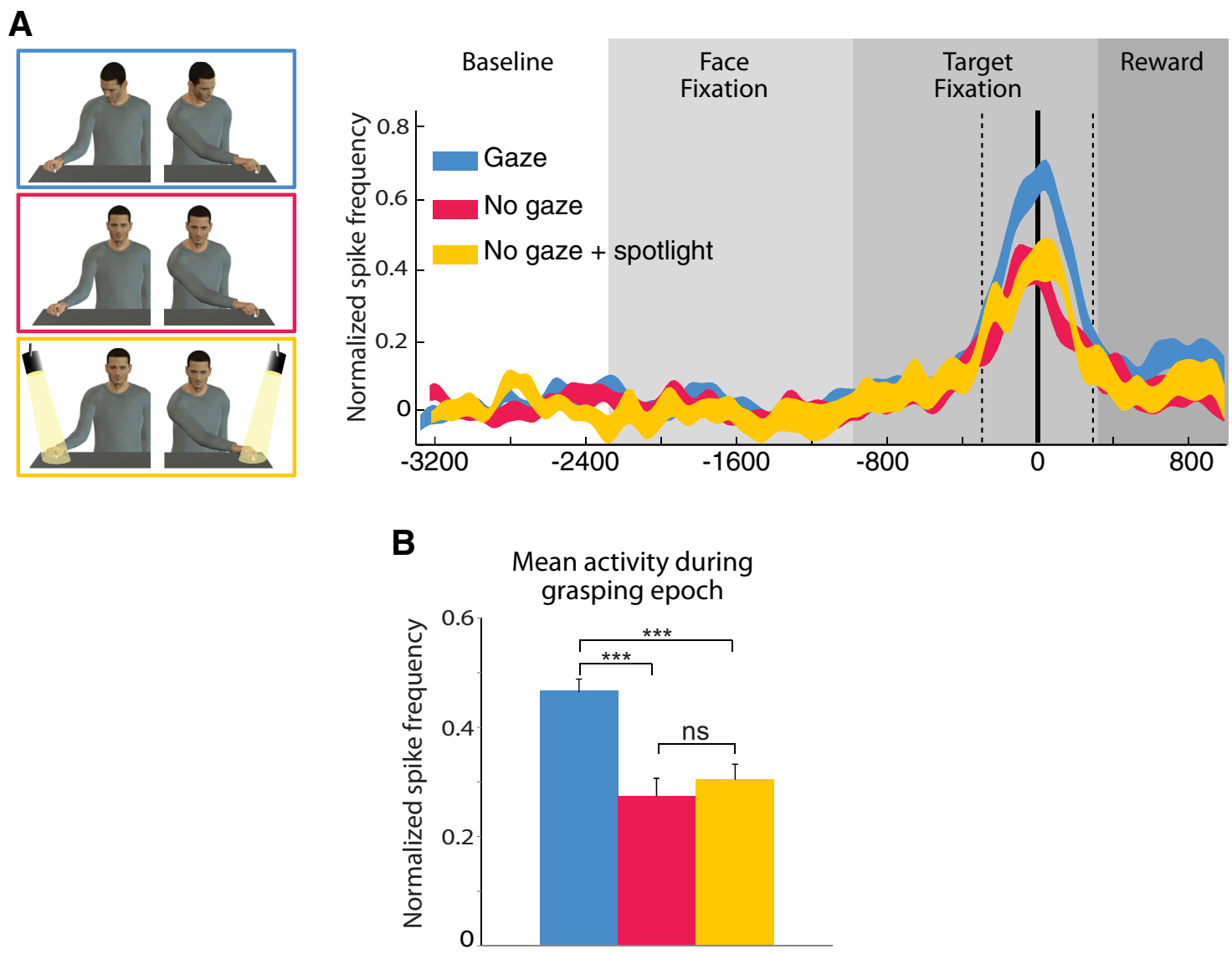

Figure 7. Analysis of the congruent gaze MN population response to congruent gaze condition (gaze; blue), No gaze shift condition (no gaze; red), and no gaze shift + spotlight condition (no gaze + spotlight; yellow). $A$, As a population, congruent neurons clearly have an increased modulation for gaze over conditions in which there was no gaze shifts. $\boldsymbol{B}$, Mean normalized discharge during the grasping epoch. Population of 40 excitatory neurons preferring congruent gaze. Conventions are the same as Figure 5.

We also tested possible discharge differences related to agent's and monkey's gaze at the neuronal population level. We plotted neuronal population data according to preferred (blue) and nonpreferred gaze direction (yellow) of the same 59 excitatory neurons (Fig. 11A). We compared the normalized discharge and did not find any significant differences between the preferred gaze and the non-preferred gaze conditions, neither when aligned with agent's gaze (Pref gaze $0.04 \pm 0.13$ vs Non-pref gaze $0.03 \pm$ $0.12, t=0.69, \mathrm{df}=58, p=0.59$, n.s., nor when aligned with the monkey's own gaze (Pref gaze $0.10 \pm 0.02$ vs Non-pref gaze $0.09 \pm 0.02, t=0.34, \mathrm{df}=58, p=0.73$, n.s.; Fig. $11 B$ ).

\section{Discussion}

The main finding of the present study is that MNs activity in PMv is modulated by the gaze direction of an observed agent during grasping. It is known that MNs can discriminate between similar motor acts, based on physical cues that allow the observer to predict different final outcomes (Fogassi et al., 2005; Bonini et al., 2011, 2012). In the present study we found that this MNs property is not limited to physical cues, but extends to social signals like gaze direction, suggesting that several cues necessary to support an integrated representation of others' intentional behavior converge in the PMv cortex.

\section{Congruence of gaze with grasping direction}

Our data show that gaze-sensitive neurons are evenly distributed in the two categories, showing preference for congruent or incongru- ent gaze direction. Neurons pertaining to the former category were expected, because from the early stages of postnatal development gaze behavior is naturally coordinated with arm direction during the execution of a reaching/grasping task (von Hofsten and Rönnqvist, 1988; Johansson et al., 2001; Crawford et al., 2004). This coupling between hand and gaze behavior is also the most frequently observed since infancy. The importance of this coordination is also confirmed by a series of behavioral studies on eye-hand integration in humans, showing that hand reaching toward objects is affected when gaze is diverted from the target (Helms et al., 1991; Henriques et al., 1998, 2003; Terao et al., 2014). Altogether, these data hint that eye-hand coordination is hardwired and part of the motor program dedicated to grasping.

The fact that one-half of the recorded neurons preferred incongruent gaze and the other one-half congruent gaze suggests that over the course of the training MNs became attuned with the more frequent two sets of visual stimuli, which were equally presented. A first possible explanation of this finding involves the plasticity of the mirror mechanism as also previously reported (Ferrari et al., 2005, 2013; Umiltà et al., 2008; Rochat et al., 2010). We do not know whether, before the training, the majority of them were more attuned to the more ethologically relevant condition, namely the congruent gaze, although this could be plausible because this is the most natural situation, to which monkeys are mostly exposed. In our experiment, the monkeys were also accustomed over months of training to see, in one-half of the trials, the agent grasping an object that was not in the location 
Ipsilateral Grasping
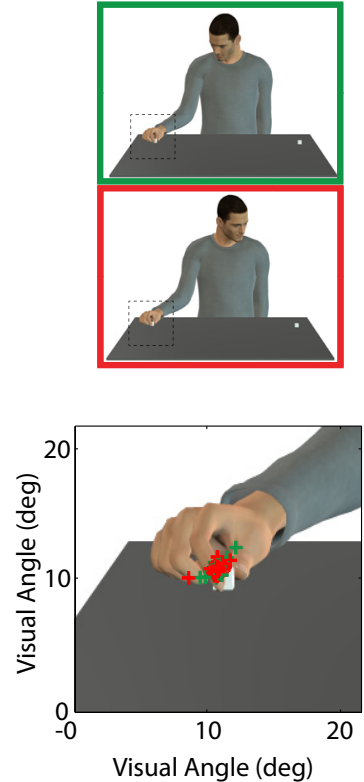

Contralateral Grasping
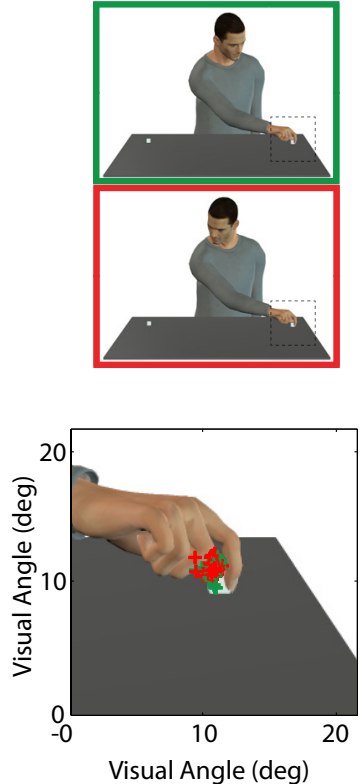

Figure 8. Monkey gaze position during grasping observation. Gaze position in the $x$ - and $y$-axes recorded at the moment in which the experimenter's hand touches the object. There is no significant difference in gaze position between congruent (green crosses) and incongruent (red crosses) conditions in neither ipsilateral nor contralateral grasp direction.

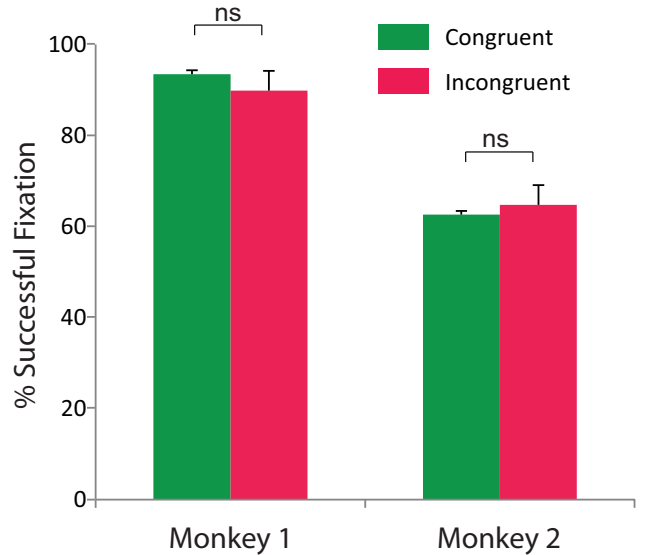

Figure 9. Mean percentage of successful fixation across all recording session for congruent and incongruent conditions for the two monkeys. There is no significant difference in fixation performance between the two conditions.

toward which his gaze was aiming. Because of this, over time, MNs might have become equally tuned to both conditions. This topic, however, needs further, possibly through chronic, electrophysiological studies.

Another possible explanation for the high percentage of MNs tuned to incongruent gaze could be related to the unusual nature of this condition, that could induce the monkey to display a different pattern of oculomotor activity from congruent gaze conditions, thus having an impact on MNs discharge (Maranesi et al., 2014). To address this criticism, we verified the oculomotor pattern of the monkey during the grasping epoch (300 ms before object contact to $300 \mathrm{~ms}$ after it), and found no difference in oculomotor patterns between the congruent and incongruent gaze conditions.
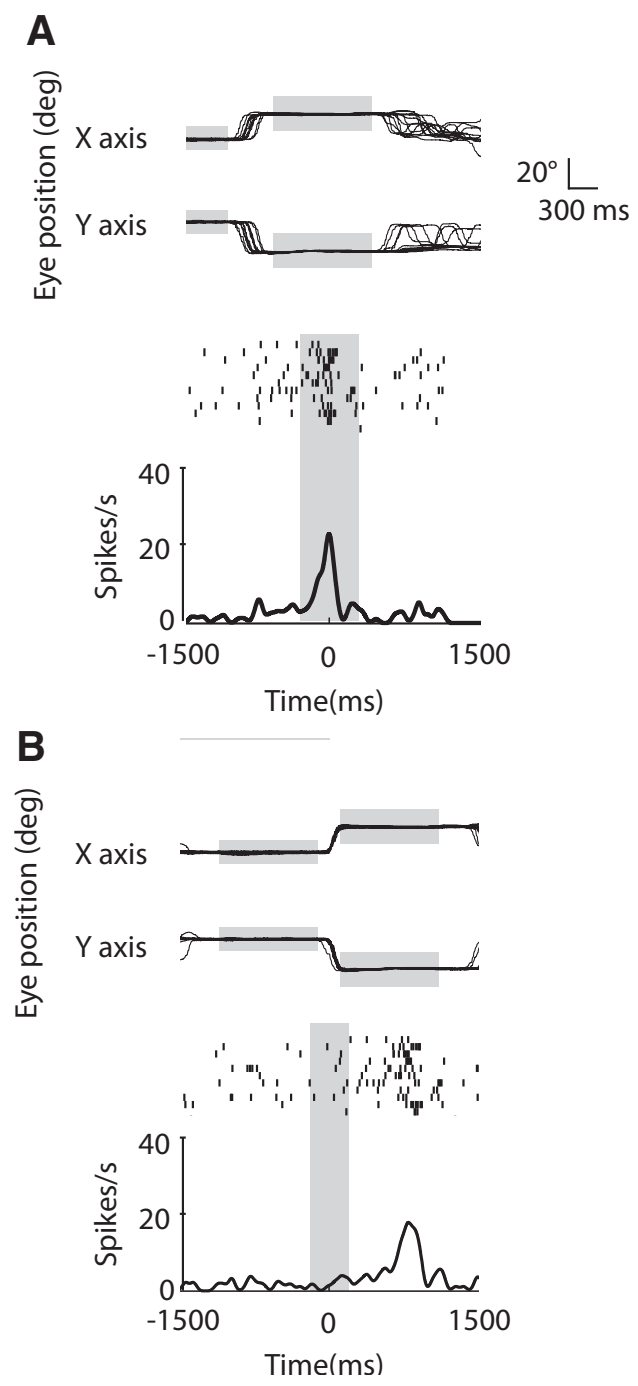

Figure 10. Examples of MN discharge with corresponding monkey gaze position where the neuronal activity and the eye traces are aligned, $(\boldsymbol{A})$ on grasping observation and $(\boldsymbol{B})$ on monkey's own gaze shift between the Face fixation window and the target fixation window. In both $\boldsymbol{A}$ and $\boldsymbol{B}$, the top traces are showing the eye position in $x$ - and $y$-axes. The height and length of the gray horizontal rectangles represents the relative fixation windows size, and the duration of the fixation, respectively. Note the stability of the eye position within each fixation window. The vertical gray rectangles represent the grasping epoch $(\boldsymbol{A})$ and the monkey gaze-shift epoch $(\boldsymbol{B})$. The neuronal discharge is time-locked to the grasping observation $(\boldsymbol{A})$, but do not change with monkey's own saccade made the same direction as the preferred gaze direction of the neuron $(\boldsymbol{B})$.

\section{Effect of grasping direction}

Previous reports showed that the space and direction in which a reaching/grasping action is performed can modulate MNs activity (Gallese et al., 1996; Caggiano et al., 2009). Our results indicate that a significant number of MNs have a preference for the direction of the grasping action, even in the absence of gaze preference (20\% of the recorded MN population). Interestingly, we found that gaze type preference, i.e., congruent and incongruent, is present mainly if it co-occurs also with a neuronal preferred grasping direction. In other words, the gaze preference of a $\mathrm{MN}$ is only relevant if grasping is performed in the neuron's preferred direction.

Altogether, our results indicate that gaze and reach-grasp direction are coupled together in area F5, despite the latter being an area mainly coding hand motor acts. They also suggest that these 

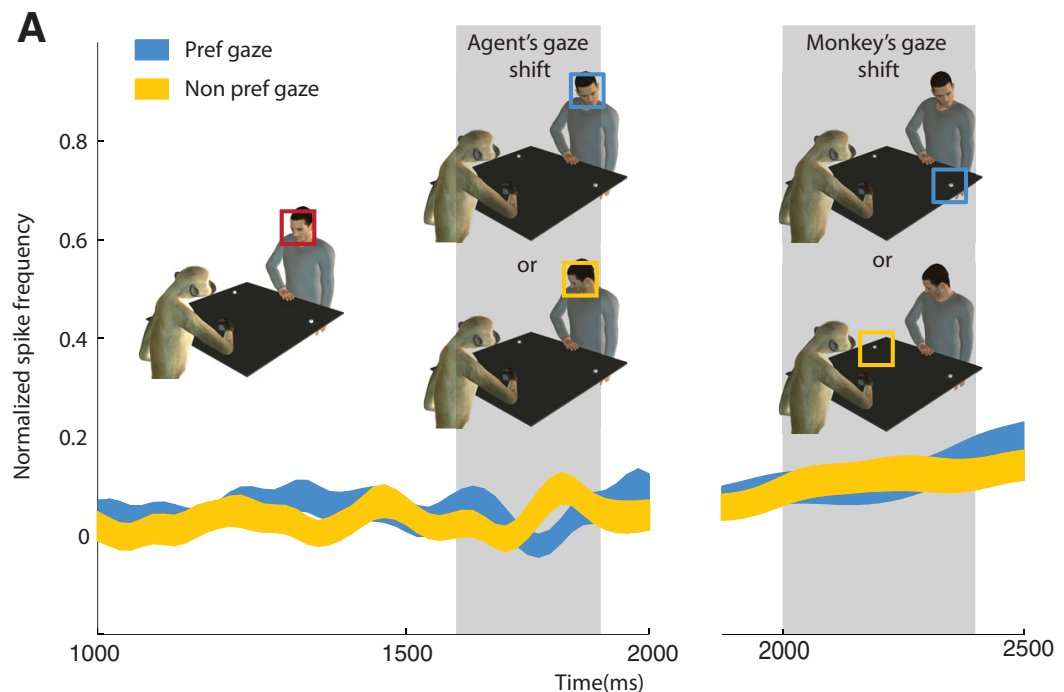

B
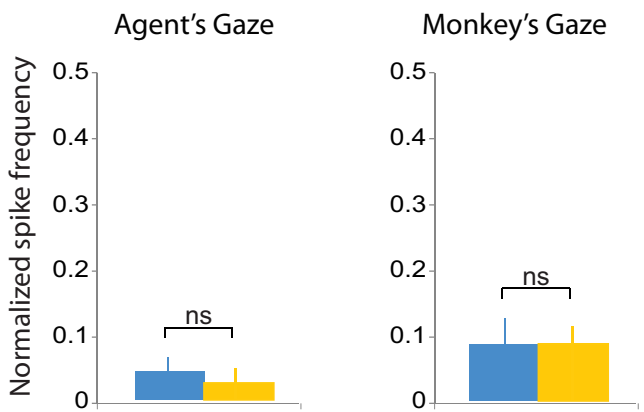

Figure 11. Analysis of gaze-modulated MN population in relation to gaze shift. $\boldsymbol{A}$, Neuronal response during agent's gaze shift for preferred gaze direction (blue square) and non-preferred gaze direction (yellow square), and ( $\boldsymbol{B}$ ) during monkey's own gaze shift. The time scale refers to the timeline of Figure 1. The gray shaded areas represent the gaze-shift epochs. Normalized activity of a population of 59 excitatory neurons (same population as Fig. 6). Note that both neurons with ipsilateral and contralateral gaze preference were included in this population. $\boldsymbol{B}$, Mean response during the epochs of gaze shift (for agent and monkey). Paired sample $t$ tests showed that the differences are not significant.

two stimuli could be critical to support the observer's capacity to correctly decode motor intentions during the observation of others' actions.

\section{Possible role of attention}

Behavioral studies in humans have demonstrated the automatic tendency to orient one's gaze in the same direction as that of the individual being observed (Driver et al., 1999; Langton et al., 2000; Vuilleumier, 2002; Deaner and Platt, 2003; Frischen et al., 2007). It can automatically redirect attention to space location where an observed gaze is aiming. Similarly to humans, macaques are capable of following gaze direction (Emery et al., 1997; Ferrari et al., 2000). One could argue that an attention shift induced by the observed gaze might be the main factor accounting for the MN activity modulation reported here. To disentangle the deictic component of gaze direction from its social aspect, we designed a spotlight condition to increase the bottom-up saliency of the target by using a light instead of the gaze cue. The spot of light pointed to the target but was devoid of the biological significance of gaze. We found that gaze had a significantly stronger effect on the neuronal discharge than the spotlight (Fig. 6). Moreover, this attentional cue had no effect on the neuronal discharge as suggested by the comparison between no gaze shift + spotlight and no gaze shift (without spotlight). Together these data indicate that gaze in itself, as a biologically meaningful signal, accounts for the neuronal modulation, rather than the mere increase in target saliency it might entail.

\section{Effect of different grasping kinematics}

It is known that while observing the action unfolding, the manner in which an object is grasped may influence the decoding of others' intention (Becchio et al., 2012). In the current experiment, the different grasping conditions could imply different kinematics that could partly contribute to the MNs differential discharge. We believe that this is unlikely, first because the neurons described in this study equally showed opposite preferences. If kinematics accounted for such preferences, we would expect only a homogeneous group of neurons sensitive for specific kinematics parameters. Second, the maximal differential discharge is present when the hand is in contact with the object, a phase of the action in which the possible differences in kinematics parameters are minimal or absent. Moreover, the differential discharge is still present during the holding phase, ruling out the kinematic account. Third, other studies showing modulation of $\mathrm{MN}$ discharge in parietal and premotor cortex during observation of grasping acts aimed at different action goals indicated that this modulation was not accounted for by different kinematics (Fogassi et al., 2005; Bonini et al., 2010).

\section{Anatomo-functional implications}

The current findings raise several questions related to the possible anatomical pathways supporting such neuronal responses. The information related to gaze direction can reach the convexity of F5 through two possible pathways. In both pathways the main sources of visual information related to gaze shift is very likely STS, where the presence of neurons responding specifically to both eyes and head turns has been reported (Jellema et al., 2000).

The first pathway may reach $\mathrm{F} 5 \mathrm{c}$ via the inferior parietal cortex (Rizzolatti and Fadiga, 1998; Nelissen et al., 2011; Rizzolatti et al., 2014), the other via the lateral prefrontal cortex (Borra et al., 2011; Gerbella et al., 2013). Regarding the first pathway, it is known that some areas of the inferior parietal cortex, such as the PFG and anterior intraparietal area, receive visual input from STS regions (Rozzi et al., 2006; Borra et al., 2008; Nelissen et al., 2011) and are containing neurons activated by the observation of hand actions (Fogassi et al., 2005; Rozzi et al., 2008; Pani et al., 2014). In addition, a neurophysiological study of the LIP, an area typically involved in oculomotor behavior and anatomically connected with STS, showed that there are neurons with mirror properties for gaze direction (Shepherd et al., 2009). It is therefore possible that visual information about others' gaze and hand actions is integrated in the parietal cortex. To our knowledge, no systematic studies have addressed this issue.

In the second possible pathway, visual information from STS region would be sent to the ventrolateral prefrontal cortex (Seltzer and Pandya, 1989a,b, 1994, 2009; 46v and area 12; Gerbella et al., 2013). Interestingly, visual and motor responses to grasp ac- 
tions has been reported in ventrolateral prefrontal cortex (Tanila et al., 1992; Hoshi et al., 1998; Nelissen et al., 2005). It is also known that in this region of the prefrontal cortex, some neurons respond specifically to faces, a property likely deriving from the specific STS region processing this biological stimulus (O Scalaidhe et al., 1997). However, no studies have investigated the possible presence of neurons sensitive to both the observation of others' gaze and hand actions in prefrontal cortex.

A key issue concerns the possible functional role of gazesensitive MNs. The modulation of F5 MNs by gaze suggests that these neurons likely use STS input as a vector of social attention. The information about gaze and action directed to a specific space location, computed first separately in STS region (with few exceptions; Jellema et al., 2000), would reach F5, very likely through the parietal cortex, and activate a joint motor representation of action and gaze direction. Such joint representation is critical during the execution of motor programs aimed at reaching and grasping objects in space. The results of this integrated internal motor representation might also be important in driving eye movements during action observation (Flanagan and Johansson, 2003) and allow the observer to proactively shift his gaze toward the grasping target to facilitate the decoding of the action during its unfolding.

It is important to note that in our paradigm, monkeys were prevented from following the gaze of the experimenter, thus dissociating the observer's gaze shift from the predicted location of the hand action. Nevertheless, gaze cue exerted a modulation on a significant number of hand MNs, suggesting that this type of social information is normally available to the premotor cortex, independently from being used in those situations in which the observer's gaze shift anticipates the behavior of the observed agent. The fact that the percentage of MNs modulated by gaze is equally subdivided between congruent and incongruent gaze/ grasping direction supports the hypothesis that gaze, as a visual social cue, can be associated to opposite behavior. Whereas congruent responses might be the expression of behaviors normally occurring during social interactions, incongruent responses, although being the results of a prolonged training, might not be functional because they are not usually displayed in macaques' interactions. However, we could speculate that the independence of the control of gaze and hand could be the precursors of more complex motor-cognitive skills in other primates, such as apes and humans, in which gaze shifts are often used to deceive conspecifics by diverting their attention from the goal of the own action.

\section{References}

Becchio C, Cavallo A, Begliomini C, Sartori L, Feltrin G, Castiello U (2012) Social grasping: from mirroring to mentalizing. Neuroimage 61:240-248 CrossRef Medline

Bonini L, Rozzi S, Serventi FU, Simone L, Ferrari PF, Fogassi L (2010) Ventral premotor and inferior parietal cortices make distinct contribution to action organization and intention understanding. Cereb Cortex 20: 1372-1385. CrossRef Medline

Bonini L, Serventi FU, Simone L, Rozzi S, Ferrari PF, Fogassi L (2011) Grasping neurons of monkey parietal and premotor cortices encode action goals at distinct levels of abstraction during complex action sequences. J Neurosci 31:5876-5886. CrossRef Medline

Bonini L, Ugolotti Serventi F, Bruni S, Maranesi M, Bimbi M, Simone L, Rozzi S, Ferrari PF, Fogassi L (2012) Selectivity for grip type and action goal in macaque inferior parietal and ventral premotor grasping neurons. J Neurophysiol 108:1607-1619. CrossRef Medline

Borra E, Belmalih A, Calzavara R, Gerbella M, Murata A, Rozzi S, Luppino G (2008) Cortical connections of the macaque anterior intraparietal (AIP) area. Cereb Cortex 18:1094-1111. CrossRef Medline
Borra E, Gerbella M, Rozzi S, Luppino G (2011) Anatomical evidence for the involvement of the macaque ventrolateral prefrontal area $12 \mathrm{r}$ in controlling goal-directed actions. J Neurosci 31:12351-12363. CrossRef Medline

Caggiano V, Fogassi L, Rizzolatti G, Thier P, Casile A (2009) Mirror neurons differentially encode the peripersonal and extrapersonal space of monkeys. Science 324:403-406. CrossRef Medline

Caggiano V, Fogassi L, Rizzolatti G, Pomper JK, Thier P, Giese MA Casile A (2011) View-based encoding of actions in mirror neurons of area $\mathrm{f5}$ in macaque premotor cortex. Curr Biol 21:144-148. CrossRef Medline

Caggiano V, Fogassi L, Rizzolatti G, Casile A, Giese MA, Thier P (2012) Mirror neurons encode the subjective value of an observed action. Proc Natl Acad Sci U S A 109:11848-11853. CrossRef Medline

Calder AJ, Beaver JD, Winston JS, Dolan RJ, Jenkins R, Eger E, Henson RN a (2007) Separate coding of different gaze directions in the superior temporal sulcus and inferior parietal lobule. Curr Biol 17:20-25. CrossRef Medline

Carlin JD, Calder AJ, Kriegeskorte N, Nili H, Rowe JB (2011) A head viewinvariant representation of gaze direction in anterior superior temporal sulcus. Curr Biol 21:1817-1821. CrossRef Medline

Crawford JD, Medendorp WP, Marotta JJ (2004) Spatial transformations for eye-hand coordination. J Neurophysiol 92:10-19. CrossRef Medline Deaner RO, Platt ML (2003) Reflexive social attention in monkeys and humans. Curr Biol 13:1609-1613. CrossRef Medline

Driver J, Davis G, Ricciardelli P, Kidd P, Maxwell E, Baron-Cohen S (1999) Gaze perception triggers reflexive visuospatial orienting. Vis $\operatorname{Cogn}$ 6:509540. CrossRef

Emery NJ, Lorincz EN, Perrett DI, Oram MW, Baker CI (1997) Gaze following and joint attention in rhesus monkeys (Macaca mulatto). J Comp Psychol 111:286-293. CrossRef Medline

Ferrari PF, Kohler E, Fogassi L, Gallese V (2000) The ability to follow eye gaze and its emergence during development in macaque monkeys. Proc Natl Acad Sci U S A 97:13997-14002. CrossRef Medline

Ferrari PF, Rozzi S, Fogassi L (2005) Mirror neurons responding to observation of actions made with tools in monkey ventral premotor cortex. J Cogn Neurosci 17:212-226. CrossRef Medline

Ferrari PF, Tramacere A, Simpson EA, Iriki A (2013) Mirror neurons through the lens of epigenetics. Trends Cogn Sci 17:450-457. CrossRef Medline

Flanagan JR, Johansson RS (2003) Action plans used in action observation. Nature 424:769-771. CrossRef Medline

Fogassi L, Ferrari PF, Gesierich B, Rozzi S, Chersi F, Rizzolatti G (2005) Parietal lobe: from action organization to intention understanding. Science 308:662-667. CrossRef Medline

Frischen A, Bayliss AP, Tipper SP (2007) Gaze cueing of attention: visual attention, social cognition, and individual differences. Psychol Bull 133: 694-724. CrossRef Medline

Gallese V, Fadiga L, Fogassi L, Rizzolatti G (1996) Action recognition in the premotor cortex. Brain 119:593-609. CrossRef Medline

Gerbella M, Belmalih A, Borra E, Rozzi S, Luppino G (2010) Cortical connections of the macaque caudal ventrolateral prefrontal areas $45 \mathrm{~A}$ and 45B. Cereb Cortex 20:141-168. CrossRef Medline

Gerbella M, Borra E, Tonelli S, Rozzi S, Luppino G (2013) Connectional heterogeneity of the ventral part of the macaque area 46 . Cereb Cortex 23:967-987. CrossRef Medline

Helms SI, Flanders M, Soechting JF (1991) Information system of visual and kinesthetic. J Neurosci 11:770-778. Medline

Henriques DY, Klier EM, Smith MA, Lowy D, Crawford JD (1998) Gazecentered remapping of remembered visual space in an open-loop pointing task. J Neurosci 18:1583-1594. Medline

Henriques DY, Medendorp WP, Gielen CC a M, Crawford JD (2003) Geometric computations underlying eye-hand coordination: orientations of the two eyes and the head. Exp Brain Res 152:70-78. CrossRef Medline

Hoshi E, Shima K, Tanji J (1998) Task-dependent selectivity of movementrelated neuronal activity in the primate prefrontal cortex. J Neurophysiol 80:3392-3397. Medline

Iacoboni M, Woods RP, Brass M, Bekkering H, Mazziotta JC, Rizzolatti G (1999) Cortical mechanisms of human imitation. Science 286:25262528. CrossRef Medline

Jellema T, Baker CI, Wicker B, Perrett DI (2000) Neural representation for the perception of the intentionality of actions. Brain Cogn 44:280-302. CrossRef Medline 
Johansson RS, Westling G, Bäckström A, Flanagan JR (2001) Eye-hand coordination in object manipulation. J Neurosci 21:6917-6932. Medline

Langton SR, Watt RJ, Bruce V (2000) Do the eyes have it? Cues to the direction of social attention. Trends Cogn Sci 4:50-59. CrossRef Medline

Maranesi M, Rodà F, Bonini L, Rozzi S, Ferrari PF, Fogassi L, Coudé G (2012) Anatomo-functional organization of the ventral primary motor and premotor cortex in the macaque monkey. Eur J Neurosci 36:3376-3387. CrossRef Medline

Maranesi M, Bonini L, Fogassi L (2014) Cortical processing of object affordances for self and others' action. Front Psychol 5:538. CrossRef Medline

Nelissen K, Luppino G, Vanduffel W, Rizzolatti G, Orban GA (2005) Observing others: multiple action representation in the frontal lobe. Science 310:332-336. CrossRef Medline

Nelissen K, Borra E, Gerbella M, Rozzi S, Luppino G, Vanduffel W, Rizzolatti G, Orban GA (2011) Action observation circuits in the macaque monkey cortex. J Neurosci 31:3743-3756. CrossRef Medline

O Scalaidhe SP, Wilson FA, Goldman-Rakic PS (1997) Areal segregation of face-processing neurons in prefrontal cortex. Science 278:1135-1138. CrossRef Medline

Pani P, Theys T, Romero MC, Janssen P (2014) Grasping execution and grasping observation activity of single neurons in the macaque anterior intraparietal area. J Cogn Neurosci 26:2342-2355. CrossRef Medline

Pelphrey KA, Singerman JD, Allison T, McCarthy G (2003) Brain activation evoked by perception of gaze shifts: the influence of context. Neuropsychologia 41:156-170. CrossRef Medline

Perrett DI, Smith PA, Potter DD, Mistlin AJ, Head AS, Milner AD, Jeeves MA (1985) Visual cells in the temporal cortex sensitive to face view and gaze direction. Proc R Soc Lond B Biol Sci 223:293-317. CrossRef Medline

Puce A, Allison T, Bentin S, Gore JC, McCarthy G (1998) Temporal cortex activation in humans viewing eye and mouth movements. J Neurosci 18:2188-2199. Medline

Rizzolatti G, Fadiga L (1998) Grasping objects and grasping action meanings: the dual role of monkey rostroventral premotor cortex (area F5). Novartis Found Symp 218:81-95. Medline

Rizzolatti G, Fadiga L, Gallese V, Fogassi L (1996) Premotor cortex and the recognition of motor actions. Brain Res Cogn Brain Res 3:131-141. CrossRef Medline

Rizzolatti G, Fogassi L, Gallese V (2001) Neurophysiological mechanisms underlying the understanding and imitation of action. Nat Rev Neurosci 2:661-670. CrossRef Medline

Rizzolatti G, Cattaneo L, Fabbri-Destro M, Rozzi S (2014) Cortical mechanisms underlying the organization of goal-directed actions and mirror neuron-based action understanding. Physiol Rev 94:655-706. CrossRef Medline
Rochat MJ, Caruana F, Jezzini A, Escola L, Intskirveli I, Grammont F, Gallese V, Rizzolatti G, Umiltà MA (2010) Responses of mirror neurons in area F5 to hand and tool grasping observation. Exp Brain Res 204:605-616. CrossRef Medline

Rozzi S, Calzavara R, Belmalih A, Borra E, Gregoriou GG, Matelli M, Luppino G (2006) Cortical connections of the inferior parietal cortical convexity of the macaque monkey. Cereb Cortex 16:1389-1417. CrossRef Medline

Rozzi S, Ferrari PF, Bonini L, Rizzolatti G, Fogassi L (2008) Functional organization of inferior parietal lobule convexity in the macaque monkey: electrophysiological characterization of motor, sensory and mirror responses and their correlation with cytoarchitectonic areas. Eur J Neurosci 28:1569-1588. CrossRef Medline

Seltzer B, Pandya DN (1989a) Frontal lobe connections of the superior temporal sulcus in the rhesus monkey. J Comp Neurol 281:97-113. CrossRef Medline

Seltzer B, Pandya DN (1989b) Intrinsic connections and architectonics of the superior temporal sulcus in the rhesus monkey. J Comp Neurol 290: 451-471. CrossRef Medline

Seltzer B, Pandya DN (1994) Parietal, temporal, and occipital projections to cortex of the superior temporal sulcus in the rhesus monkey: a retrograde tracer study. J Comp Neurol 343:445-463. CrossRef Medline

Seltzer B, Pandya DN (2009) Posterior cingulate and retrosplenial cortex connections of the caudal superior temporal region in the rhesus monkey. Exp Brain Res 195:325-334. CrossRef Medline

Shepherd SV, Klein JT, Deaner RO, Platt ML (2009) Mirroring of attention by neurons in macaque parietal cortex. Proc Natl Acad Sci U S A 106: 9489-9494. CrossRef Medline

Tanila H, Carlson S, Linnankoski I, Lindroos F, Kahila H (1992) Functional properties of dorsolateral prefrontal cortical neurons in awake monkey. Behav Brain Res 47:169-180. CrossRef Medline

Terao Y, Andersson NE, Flanagan JR, Johansson R (2002) Engagement of gaze in capturing targets for future sequential manual actions. J Neurophysiol 88:1716-1725. Medline

Umiltà MA, Escola L, Intskirveli I, Grammont $\mathrm{F}$, Rochat $\mathrm{M}$, Caruana $\mathrm{F}$, Jezzini A, Gallese V, Rizzolatti G (2008) When pliers become fingers in the monkey motor system. Proc Natl Acad Sci U S A 105:2209_ 2213. CrossRef Medline

von Hofsten C, Rönnqvist L (1988) Preparation for grasping an object: a developmental study. J Exp Psychol Hum Percept Perform 14:610-621. CrossRef Medline

Vuilleumier P (2002) Perceived gaze direction in faces and spatial attention: a study in patients with parietal damage and unilateral neglect. Neuropsychologia 40:1013-1026. CrossRef Medline 